\title{
Renewable water: direct contact membrane distillation coupled with solar
}

Francisco Suárez ${ }^{1,2^{*}}$, Jeffrey A. Ruskowitz ${ }^{3}$, Scott W. Tyler $^{3}$, Amy E. Childress ${ }^{4}$

${ }^{1}$ Departmento de Ingeniería Hidráulica y Ambiental, Pontificia Universidad Católica de Chile. Av. Vicuña Mackenna 4860, Santiago, Chile. Casilla 306, Correo 22, Santiago, Chile.

${ }^{2}$ Centro de Desarrollo Urbano Sustentable (CEDEUS), CONICYT/FONDAP/15110020, Santiago, RM, Chile.

${ }^{3}$ Department of Geological Sciences and Engineering, University of Nevada, Reno. 1664 N. Virginia St. MS 172, Reno NV 89557, USA.

${ }^{4}$ Sonny Astani Department of Civil and Environmental Engineering, University of Southern California. 3260 S.

17 Vermont Ave; KAP 210, Los Angeles, CA 90089-2531.

${ }^{*}$ Correspondence to: Francisco Suárez. Phone: 56-2-2354-4227; Fax: 56-2-2354-5876.

E-mail addresses: fsuarez@ing.puc.cl (F. Suárez), ruskowitz@gmail.com (J. Ruskowitz), styler@unr.edu (S. Tyler), amyec@usc.edu (A. Childress) 


\section{Abstract}

Desalination powered by renewable energy sources is an attractive solution to address the worldwide water-shortage problem without contributing significant to greenhouse gas emissions. A promising system for renewable energy desalination is the utilization of low-temperature direct contact membrane distillation (DCMD) driven by a thermal solar energy system, such as a saltgradient solar pond (SGSP). This investigation presents the first experimental study of fresh water production in a coupled DCMD/SGSP system. The objectives of this work are to determine the experimental fresh water production rates and the energetic requirements of the different components of the system. From the laboratory results, it was found that the coupled DCMD/SGSP system treats approximately six times the water flow treated by a similar system that consisted of an air-gap membrane distillation unit driven by an SGSP. In terms of the energetic requirements, approximately $70 \%$ of the heat extracted from the SGSP was utilized to drive thermal desalination and the rest was lost in different locations of the system. In the membrane module, only half of the useful heat was actually used to transport water across the membrane and the remainder was lost by conduction in the membrane. It was also found that by reducing heat losses throughout the system would yield higher water fluxes, pointing out the need to improve the efficiency throughout the DCMD/SGSP coupled system. Therefore, further investigation of membrane properties, insulation of the system, or optimal design of the solar pond must be addressed in the future.

\section{Introduction}

Global population growth and higher standards of living are significantly increasing the demand for energy and water [[1]]. Fossil fuels have been used to meet the energy needs, but are not sustainable due to the environmental impacts of combustion and the rapid depletion of fossil fuel reserves [2-4]. Thus, renewable energy sources are needed to reduce fossil fuels consumption and to increase fresh water production. 

osmosis (RO) has been the most common method for desalination, especially since the cost of membranes has decreased over the years [5]. However, RO requires significant quantities of energy [6]. Desalination powered by renewable energy sources is an attractive solution, because it has lower environmental impacts and lower greenhouse gas emissions [7-9]. In fact, novel temperaturedriven membrane techniques can produce fresh water at a competitive cost, and can be very effective to desalinate brackish water, seawater, or even brines [10,11].

A promising approach to desalination is low-temperature membrane distillation (MD) driven by thermal solar energy [12]. This approach may be especially well-suited to arid regions, where there is a fresh water shortage, a salt water surplus, and high availability of solar energy [13]. MD is a temperature-driven membrane separation process that has the potential to become a viable tool for water desalination [14-17].

An ideal, renewable source of heat for MD systems is a salt-gradient solar pond (SGSP). An SGSP is a body of water that collects solar radiation and utilizes a salt gradient in order to store this collected solar radiation as thermal energy [18]. Most common SGSPs consist of three distinct layers: the upper convective zone (UCZ), the non-convective zone (NCZ), and the lower convective zone (LCZ). The UCZ consists of the least saline water and is located in the uppermost section of the solar pond. The NCZ consists of an increasing saline solution with increasing depth and is located below the UCZ. The salinity gradient present in the NCZ suppresses any mixing between the three layers while still allowing solar radiation to penetrate through the solar pond into the LCZ. The LCZ consists of the most saline, and thus, most dense solution and is located below the NCZ, making up the bottom of the solar pond. As the LCZ collects solar radiation and rises in temperature, the high salinity solution remains trapped below the NCZ due to its density. This salinity (or density) gradient allows the LCZ to collect and store solar energy for long periods of time [19]. Temperatures higher than $80{ }^{\circ} \mathrm{C}$ have been observed in previous studies [20-22], while temperatures as high as $110{ }^{\circ} \mathrm{C}$ have been observed in an outdoor solar pond, with a temperature 
difference between the UCZ and LCZ of nearly $70{ }^{\circ} \mathrm{C}$ [23]. A major advantage of using a solar pond for energy collection and storage are low costs of construction and operation, especially when compared to photovoltaic cells [24].

When a solar pond is exposed to solar radiation, energy is collected and stored in the LCZ. This stored energy, or heat, can be easily extracted from the solar pond through heat exchangers and utilized for applications such as thermal desalination by direct contact membrane distillation (DCMD) [25]. DCMD is the simplest configuration of MD where the warmer feed solution and cooler distillate solution are in direct contact with both sides of the membrane [14]. The driving force is the vapor pressure gradient that is induced across the membrane from contact of the warmer and cooler streams. Previous studies have shown that DCMD is advantageous for obtaining high fluxes [26] but does suffer from heat losses due to conduction through the membrane surface [24]. The simplicity of DCMD, requiring only a membrane module, low-grade heat source, and two lowpressure pumps, makes it very suitable to be coupled with an SGSP for solar powered thermal desalination.

Solar ponds have been previously used to provide heat for various forms of desalination. A 3,000 $\mathrm{m}^{2}$ solar pond in El Paso, Texas was used to deliver heat for both a multi-stage flash distillation (MSF) unit and an air-gap MD (AGMD) unit [20]. The MSF unit was able to produce water at $3.3 \mathrm{~L} \mathrm{~min}^{-1}$, or $1.6 \times 10^{-3} \mathrm{~m}^{3} \mathrm{~d}^{-1}$ per $\mathrm{m}^{2}$ of SGSP, while the AGMD unit was able to produce water at $6.7 \mathrm{~L} \mathrm{~m}^{-2} \mathrm{~h}^{-1}$, or $0.158 \times 10^{-3} \mathrm{~m}^{3} \mathrm{~d}^{-1}$ per $\mathrm{m}^{2}$ of SGSP. The desalination research performed at the El Paso Solar Pond demonstrated that desalination driven by solar ponds on a large scale is feasible and competitive with other desalination techniques [22]. However, most of the investigations where solar ponds deliver heat for thermal desalination correspond to performance analysis [25,27,28]. Suárez et al. [25] studied a coupled DCMD/SGSP system that has potential to produce four times the expected water fluxes in an AGMD/SGSP system. Saleh et al. [27] studied the coupling of a solar pond with an MSF desalination unit. Mericq et al. [28] investigated the coupling of vacuum MD with solar ponds and solar collectors. These investigations only studied the 
105

previous configurations by means of theoretical models and no experimental validation was performed.

The objective of this study is to experimentally evaluate, for the first time, the performance of a synergetic DCMD/SGSP system to achieve solar-powered thermal desalination. The specific objectives of this work are to determine: 1) the experimental fresh water production rates; and 2) the energetic requirements of the different components of the DCMD/SGSP system. An SGSP is a promising renewable energy system that can deliver low-grade heat to desalination systems. Coupling an SGSP with a simplistic desalination system such as DCMD allows for remote desalination with very little electrical input; thus, reducing fossil fuels consumption and increasing fresh water production in a sustainable way.

\section{Materials and methods}

\subsection{Solar pond}

This study used the laboratory-scale solar pond constructed by Suárez et al. [29]. Complete details on the pond's instrumentation are presented in previous works [29,30]. For this investigation, the pond was modified to allow heat extraction (Figure 1). Two sets of diffusers were installed at $\sim 0.5 \mathrm{~m}$ depth at both sides of the pond. This depth was selected because it was intended to be just below the interface between the NCZ and LCZ. Brine was recirculated at a rate of $3.00 \mathrm{~L} \mathrm{~min}^{-1}$ using a gear pump (Cole-Parmer ${ }^{\circledR}$ Gear Pump Systems, Cole-Parmer Instrument Company, Vernon Hills, IL). The hot brine was taken from one side of the pond, passed through a plumbing system that was connected to a custom-made heat exchanger (used to extract the collected heat), and then the cooler brine was returned to the other side of the pond. The plumbing outside the solar pond is comprised of $1.27-\mathrm{cm}(1 / 2-$ inch $)$ diameter polyvinyl chloride (PVC) pipes. The pipes were insulated using self-seal polyethylene foam pipe insulation (Tubolit ${ }$, Armacell, Mebane, NC). The heat exchanger was used to extract heat from the solar pond to warm the feed solution of the DCMD test 
unit. The heat exchanger consisted of approximately twenty $0.64-\mathrm{cm}(1 / 4-\mathrm{inch})$ stainless steel tubes inside a 5.1-cm (2-inch) diameter PVC pipe. The heat exchanger was also insulated with self-seal polyethylene foam pipe insulation.

\subsection{DCMD test unit}

The DCMD module used in this study (MD 020 CP 2N, Microdyn, Wiesbaden, Germany) contained 40 capillary membranes of 1.8 and $2.8 \mathrm{~mm}$ inner and outer diameter, respectively, an active length of $460 \mathrm{~mm}$, a surface area of $0.1 \mathrm{~m}^{2}$, and a free flow area of $1 \mathrm{~cm}^{2}$. The polypropylene membrane has an average pore size of $0.2 \mu \mathrm{m}$, a porosity of $70 \%$, a tortuosity of 1.43 [31], and an average effective thermal conductivity of $0.046 \mathrm{~W} \mathrm{m-1}{ }^{\circ} \mathrm{C}-1$ [32].

Fresh water was used as the feed solution and was continuously pumped at a rate of $1.25 \mathrm{~L}$ $\mathrm{min}^{-1}$ from a feed reservoir through the heat exchanger (that is connected to the solar pond), across the membrane module and back to the feed reservoir (Figure 1). The fresh water feed allows evaluating the best-case scenario for membrane flux. The assessment of fouling mitigation (e.g., evaluation of feed water pretreatment, selection of the most appropriate membrane for the solution chemistry, optimization of the flow conditions to minimize deposition of foulant material) is outside the scope of this study. Distilled deionized water was used as the distillate solution and was recirculated at a rate of $2 \mathrm{~L} \mathrm{~min}^{-1}$ in the distillate loop in the same way as the feed loop (Figure 1). The distillate solution was cooled to the desired temperature with a heat exchanger fed by a water chiller (ISOTEMP 1023S, Fisher Scientific, Pittsburg, PA). The distillate reservoir was a 2 L filtration flask that allows overflow of excess permeating water into a collecting flask. The overflow was continuously weighed on an analytical balance (PGL 8001, Nova-Tech International, Houston, TX), which allowed estimation of the water fluxes across the membrane.

Electrical conductivity (EC) and temperature (T) in different locations of the DCMD test unit (Figure 1) were measured using EC electrodes (SK23T, Van London-pHoenix Company, Houston, TX). A modular multi-channel datalogger (D230, Consort, Turnhout, Belgium) was used 
to record these data at 5-min intervals. Pressure within the DCMD system was not measured since it

operated at near atmospheric pressure (approximately 0.9 atm). Acrylic flowmeters (FR4000, Key Instruments, Trevose, PA) were installed after each pump (Cole-Parmer ${ }^{\circledR}$ Gear Pump Systems, Cole-Parmer Instrument Company, Vernon Hills, IL) to control the flow rates of the DCMD feed and permeate streams.

\subsection{Thermal desalination driven by solar ponds}

For the experiment, the lights over the laboratory-scale solar pond were turned on 24 hours per day, with an average radiation at the water surface of $240 \pm 3 \mathrm{~W} \mathrm{~m}^{-2}$. Temperature within the solar pond was monitored throughout the experiment using a vertical high-resolution distributed temperature sensing (DTS) system $[29,33]$. This DTS system achieves a temperature resolution of $\pm 0.06{ }^{\circ} \mathrm{C}$ when data were integrated over $30 \mathrm{~s}$. The thermal desalination experiment began when thermal quasi steady-state conditions were achieved inside the solar pond. Heat was extracted for 45 hours at $\sim 0.5 \mathrm{~m}$ depth (by the two sets of diffusers).

An energy balance was carried out on the solar pond-powered desalination system to determine the energy used in each component of the system. The heat extracted from the solar pond, $q_{\mathrm{USE}}^{\prime \prime}$, was estimated using the heat content inside the solar pond [34]. The heat used in the membrane module, $q_{\mathrm{m}}$, was estimated using a previously developed heat and mass transfer model for DCMD [25] (This model is briefly described below). Conductive heat losses in the solar pond plumbing, $q_{\mathrm{SGSP}}^{\text {cond }}$, were calculated using the temperature at the extraction depth inside the solar pond as an approximate temperature for the bulk temperature within the pipes and the temperature of the laboratory as the ambient temperature. The thermal properties of the PVC pipes and the self-seal foam pipe insulation were used to determine the radial conductive flow through this part of the system. Other heat losses throughout the system, $q_{\mathrm{SYST}}^{\text {other }}$, were estimated by subtracting $q_{\mathrm{SGSP}}^{\text {cond }}$ and $q_{\mathrm{m}}$ from the heat extracted from the solar pond. 

used in the membrane module and the water flux across the membrane. In this model, the water

180 flux, $J$, across the membrane is estimated by [35]:

$$
J=C_{\mathrm{m}}\left[p_{\mathrm{fm}}\left(T_{\mathrm{fm}}, S_{\mathrm{fm}}\right)-p_{\mathrm{dm}}\left(T_{\mathrm{dm}}\right)\right]
$$

where $C_{\mathrm{m}}$ is the distillation coefficient of the membrane, $p$ is the vapor pressure, $T$ is the temperature, and $S$ is the feed concentration. The subscripts "fm" and "dm" represent the feed and distillate sides of the membrane surface, respectively. At steady-state conditions, a heat transfer analysis yields:

$$
q_{\mathrm{f}}=q_{\mathrm{m}}=q_{\mathrm{d}}
$$

where $q_{\mathrm{f}}$ and $q_{\mathrm{d}}$ are the convective heat transfer in the feed and distillate, respectively; and $q_{\mathrm{m}}$ is the heat transferred across the membrane. These heat fluxes are given by:

$$
\begin{gathered}
q_{\mathrm{f}}=h_{\mathrm{f}}\left(T_{\mathrm{f}}-T_{\mathrm{fm}}\right) \\
q_{\mathrm{d}}=h_{\mathrm{d}}\left(T_{\mathrm{dm}}-T_{\mathrm{d}}\right) \\
q_{\mathrm{m}}=q_{\mathrm{m}}^{\mathrm{c}}+q_{\mathrm{m}}^{\mathrm{v}}=\left[k_{\mathrm{m}} \frac{d T}{d x}\right]+\left[J H_{\mathrm{v}}(T)\right]
\end{gathered}
$$

where $h_{\mathrm{f}}$ and $h_{\mathrm{d}}$ are the heat transfer coefficients in the feed and distillate, respectively; $T_{\mathrm{f}}$ and $T_{\mathrm{d}}$ are the bulk temperatures in the feed and distillate, respectively; $q_{\mathrm{m}}^{\mathrm{c}}$ is the conductive heat flux through the membrane; $q_{\mathrm{m}}^{\mathrm{v}}$ is the enthalpy heat flux through the membrane; $k_{\mathrm{m}}$ is the effective thermal conductivity of the membrane; $x$ is the distance in the mass flux direction; and $H_{\mathrm{v}}(T)$ is the vapor enthalpy (latent heat of vaporization) at temperature $T$. A detailed description of the model is presented elsewhere $[25,36]$. The input parameters of the mathematical model were based on the properties of the membrane (described above), and the operating conditions monitored during the experiments. Table 1 presents a summary of the values of the input parameters that were used in the numerical simulations. Note that the mathematical model allows disaggregating the heat fluxes that govern the physics of the DCMD unit. Hence, model results give insights on the parts of the system 
that require improvement and the parts of the system that are working properly. Also, it is important to mention that assessing the effect of fouling on the energetic aspects of the DCMD/SGSP system is out of the scope of this work.

Monte Carlo simulations were performed to quantitatively estimate the uncertainty of the water flux across the membrane and the energy used in each component of the system, i.e., to analyze how the uncertainty of the operating parameters and membrane properties affect the water and heat fluxes in the coupled system. These simulations were based on the energy balance explained above. Table 1 shows the probability distribution of the input parameters used in the Monte Carlo simulations. The input parameters of the Monte Carlo simulations were based on the experimental measurements and on values obtained from the literature $[31,32]$.

\section{Results and discussion}

\subsection{Heat extraction in the solar pond}

The thermal behavior of the solar pond before, during, and after the desalination experiment is shown in Figure 2. Data collected from the vertical high-resolution DTS system [29] were integrated over $30 \mathrm{~s}$ intervals to achieve a temperature resolution of $0.06{ }^{\circ} \mathrm{C}$. Before the desalination experiment began, thermal quasi-steady state and a temperature of $\sim 45^{\circ} \mathrm{C}$ were reached in the LCZ. Heat extraction started at 12:12 p.m. on January 19, 2010. Figure 2 clearly shows pond cooling in the lower depths during heat extraction and pond warming in the lower depths soon after heat extraction stopped. Figure 3 (a) shows the temperature profile before heat extraction (black line), after approximately 1 and 2.5 hours of experimentation (blue and red lines, respectively), and at approximately 45 hours, which is the end of the heat extraction period (green line). The time period between 1 and 2.5 hours was plotted because during this timeframe the desalination system achieved steady-state conditions. This steady-state allowed estimation of the heat used in the desalination process (discussed below). After $60 \mathrm{~min}$ of extracting heat, the temperature profile 
already showed the existence of different layers inside the solar pond (Figure 2). Initially, the NCZ-

LCZ interface was intended to be at a depth of $\sim 0.5 \mathrm{~m}$. However, the interface actually occurred at a depth more deep than $0.5 \mathrm{~m}$. During the first 2.5 hours of the desalination experiment, it is likely that heat was extracted from the NCZ rather than from the LCZ (Figure 3 (a)). After 45 hours of heat extraction, the thermal structure inside the solar pond (green line) reveals that even though energy is being extracted from the NCZ, there is energy likely coming from the LCZ. When the temperatures at the extraction depth are cooler than some threshold, the fluid at this depth become heavier and thus, sinks into the bottom of the pond, which has been shown to produce a rise of the warmer brine [37].

The temperature profiles measured inside the solar pond were used to determine the heat content throughout the pond. Figure 3 (b) presents the temporal evolution of the heat content, which has an error of $0.2 \mathrm{MJ}$ (due to the temperature resolution of the DTS system). The slope of this curve represents the heat extracted from the solar pond. An average of $139 \pm 12 \mathrm{~W}$ was extracted from the solar pond during the 45 hours of operation. This corresponds to an efficiency of $29 \%$. Efficiencies between 4 and 35\% have been reported in other solar ponds studies [38-40]. During the first 2.5 hours of experimentation, an average of $230 \pm 20 \mathrm{~W}$ (efficiency of $48 \%$ ) was extracted from the pond (Figure 3 (b) inset). In calculating heat extraction, only the heat content below $0.20 \mathrm{~m}$ depth was considered as heat used for extraction. Changes in the heat content at shallower depths could have been the result of changes at the surface of the pond, e.g., due to evaporation or to fresh water injection to account for evaporation. It has also been found that operation of the solar pond at lower temperatures decreases conductive heat losses throughout the NCZ, which results in more useful energy that can be used in the desalination system [25]. In this experiment, $6 \%$ of the incoming energy was lost due to conductive heat losses when the LCZ of the solar pond was at 45 ${ }^{\circ} \mathrm{C}$. When the $\mathrm{LCZ}$ was at $39^{\circ} \mathrm{C}$, a $56 \%$ reduction of the conductive heat losses was estimated. Although this additional energy is relatively small, reduced conductive heat losses are an advantage of this system compared to systems that operate at higher temperatures. 
The results presented in Figure 3 suggest that the solar pond is far from reaching steadystate conditions when heat is being extracted from the system. As discussed by Suárez et al. [25], to operate a DCMD/SGSP system under thermal steady-state conditions, the surface area of the solar pond must be on the order of 1,000 times the membrane surface area. In this experimental system, a solar pond with surface area of $2 \mathrm{~m}^{2}$ is being used to provide energy to a DCMD module with 0.1 $\mathrm{m}^{2}$ of membrane surface area, and thus the surface area of the solar pond is only 20 times that of the membrane. As can be seen in Figures 2 and 3, by the inability of the pond to maintain steady-state conditions, the solar pond essentially cannot keep up with the MD system. The desalination system would thus have to be operated intermittently to maintain a viable thermal structure in the solar pond. Because it is not efficient to have a larger membrane area operating intermittently, use of a smaller membrane area is desired not only for continuous operation but also for lower capital costs.

\subsection{Thermal desalination driven by solar ponds}

Figure 4 (a) shows water flux through the membrane and cumulative distillate throughout the experiment. The experimental errors associated to the water flux and to the cumulative distillate were estimated on $0.01 \mathrm{~L} \mathrm{hr}^{-1}$ per $\mathrm{m}^{2}$ of membrane and on $1 \times 10^{-4} \mathrm{~L}$, respectively. A maximum water flux of $\sim 1.1 \mathrm{~L} \mathrm{hr}^{-1}$ per $\mathrm{m}^{2}$ of membrane was observed during the first 8 hours of the experiment. After this, the water flux decreased most likely due to a reduction in the feed temperature caused by a decrease in the solar pond temperature (as explained in section 3.1 and as seen in Figure 2). Flux decline due to fouling or scaling is not likely because the membrane module was operated with fresh water as the feed solution. Also, electrical conductivity in the distillate reservoir did not change significantly over time, thus wetting of the membrane pores was not observed.

A total of $3.3 \mathrm{~L}$ of water were produced during the first 34 hours of the experiment. After this time, the analytical balance turned off and no record of treated water was available. This water production corresponds to an average water flux of $0.97 \pm 0.09 \mathrm{~L} \mathrm{hr}^{-1}$ per m $\mathrm{m}^{2}$ of membrane, which is 
equivalent to $\sim 1.16 \times 10^{-3} \mathrm{~m}^{3} \mathrm{~d}^{-1}$ per $\mathrm{m}^{2}$ of solar pond. However, this water flux is not sustainable 278 over time because the coupled system was not optimized to operate at steady-state conditions. It 279 was found that the solar pond required approximately 10 days to recover its initial thermal structure 280 after heat extraction was stopped (data not shown). This results in an actual flow rate of $\sim 0.12 \times 10^{-3}$ $281 \mathrm{~m}^{3} \mathrm{~d}^{-1}$ per $\mathrm{m}^{2}$ of solar pond, which is actually on the same order as the maximum treated flow rate 282 obtained by an AGMD unit tested at the 3,000- $\mathrm{m}^{2}$ El Paso Solar Pond [41]. A maximum treated 283 flow of $\sim 0.16 \times 10^{-3} \mathrm{~m}^{3} \mathrm{~d}^{-1}$ per $\mathrm{m}^{2}$ of solar pond $\left(6.7 \mathrm{~L} \mathrm{hr}^{-1}\right.$ per $\mathrm{m}^{-2}$ of membrane $)$ was obtained by 284 the AGMD system. This water production was obtained using clean water as the feed solution and 285 with feed and distillate temperatures of 69.6 and $28.5^{\circ} \mathrm{C}$, respectively, i.e., at a temperature 286 difference across the membrane of $41.1{ }^{\circ} \mathrm{C}$. The average temperature difference across the 287 membrane in the current work is approximately $10^{\circ} \mathrm{C}$ (Figure 4 (b)) with feed and distillate average 288 temperatures of $34.3 \pm 0.1$ and $24.0 \pm 0.1{ }^{\circ} \mathrm{C}$, respectively (feed and distillate average temperatures 289 were calculated using the inlet and outlet temperature of each stream). When the temperature 290 difference in the AGMD system decreased to approximately $10^{\circ} \mathrm{C}$ [41], the AGMD system treated 291 approximately 6 times less water than that treated by the DCMD system presented in this work. No 292 information was found regarding temperature reduction inside the El Paso Solar Pond while the 293 AGMD system was operating. To our knowledge, no other experimental studies of membrane 294 distillation driven by solar ponds exist except El Paso's AGMD/SGSP [20,22,41]. Although, it 295 should be noted that the El Paso's system used an outdoor large-scale solar pond and a membrane 296 distillation unit that was approximately 30 times larger than that used in this work.

Figure 4 (b) also presents the water flux of the DCMD module during the first 2.5 hours of experimentation, where steady-state conditions were observed. At the beginning of the experiment, 299 the temperatures in the desalination system increased until steady state was reached. A water flux of $3001.08 \pm 0.01 \mathrm{~L} \mathrm{hr}^{-1}$ per $\mathrm{m}^{2}$ of membrane was obtained in this steady-state time period. The heat and 301 mass transfer model for the DCMD module [25] was used to estimate the theoretical water flux and 
energy requirements of the desalination system. The results of the heat and mass transfer model are presented in Figure 4 (b). It can be seen that the water fluxes obtained using the heat and mass transfer model agree fairly well with the experimental data, with differences less than $6 \%$.

The results of the Monte Carlo simulations are shown in Figure 5 and Table 2. Figure 5 presents the histogram of the water flux across the membrane and provides further confirmation of the agreement between the modeled and experimental water fluxes. Table 2 presents the results of the energy budget of the DCMD/SGSP system. As shown in Table 2, approximately $70 \%$ of the energy extracted from the solar pond was used to drive thermal desalination, i.e., $q_{\mathrm{m}}=0.7 q_{\mathrm{USE}}^{\prime \prime}$, approximately half of this energy is used to transport water across the membrane (the enthalpy flow, $\left.q_{\mathrm{m}}^{\mathrm{v}}\right)$, and the remainder is lost by conduction in the membrane $\left(q_{\mathrm{m}}^{\mathrm{c}}\right)$. Therefore, improvement of DCMD membranes and modules to reduce conductive heat losses would yield higher water fluxes. From the energy that is not used to drive thermal desalination, approximately $20 \%$ was lost in the plumbing system of the solar pond, and the rest was lost in other parts of the system (e.g., heat exchanger, feed reservoir, feed side plumbing, or from the membrane module to the ambient). By having better insulation throughout the system more heat would be available for the desalination process, and thus, more water could be treated. For example, if $90 \%$ of the energy extracted from the solar pond is used to drive this desalination system, i.e., $q_{\mathrm{m}}=0.9 q_{\mathrm{USE}}^{\prime \prime}$, the water flux could increase from 1.08 to $1.43 \mathrm{~L} \mathrm{hr}^{-1}$ per $\mathrm{m}^{2}$ of membrane, i.e., a water production of $0.37 \times 10^{-3} \mathrm{~m}^{3} \mathrm{~d}^{-1}$ per $\mathrm{m}^{2}$ of solar pond, which corresponds to a $33 \%$ increase in the water flux. This points out the need to improve the efficiency throughout the DCMD/SGSP coupled system. Therefore, further investigation of membrane properties, insulation of the system, and optimal design of the solar pond must be addressed in the future.

It is important to note that the laboratory-scale solar pond used in this work is also subject to other energetic inefficiencies [30] that reduce the efficiency of this system; and ultimately have an impact on the energy that can be extracted and subsequent water that can be treated. For instance, 
the pond is heated with artificial lights that yield lower radiation intensities than the sun. Thus, outdoor operation of the solar pond is expected to result in higher values of treated water than those achieved with the indoor solar pond presented here. Also, the pond has a sloped wall that has two main drawbacks: (1) radiation is absorbed at shallower depths inside the pond, resulting in lower temperatures at the bottom of the pond compared to those expected in large-scale operation; and (2) the energy storage volume is reduced when compared to a large-scale solar pond where boundary effects can be neglected. Therefore, a maximum temperature of only $45^{\circ} \mathrm{C}$ was achieved in the laboratory-scale solar pond, whereas temperatures higher than $80^{\circ} \mathrm{C}$ have been observed in the majority of large-scale solar ponds [20-22,41-43]. Even more, temperatures as high as $110^{\circ} \mathrm{C}$ were observed when the brine of a solar pond was boiling [23]. Hence, even when the pond could be subject to other heat losses, e.g., due to meteorological conditions, more energy could be collected and higher water production values than those reported in this work could be achieved.

In addition to the energetic inefficiencies observed in the laboratory-scale system [30], it is important to address other issues that also reduce the overall efficiency. For instance, in a recent investigation, Ruskowitz [44] used the same solar pond of this study to evaluate the effect of evaporation suppression on both the energy collected by the solar pond and the freshwater production rates. Ruskowitz [44] obtained a maximum water production rate of $\sim 2.89 \times 10^{-3} \mathrm{~m}^{3} \mathrm{~d}^{-1}$ per $\mathrm{m}^{2}$ of solar pond when $88 \%$ of the pond surface was covered with transparent floating discs $[44,45]$. This water production rate is 2.5 times larger than that obtained in this work. Therefore, from the work of Ruskowitz [44] two conclusions can be drawn: 1) his water production rates demonstrate the reproducibility of the experimental values presented in this work; and 2) evaporation suppression at the pond surface increase both the energy collected by the solar pond and the water production rates in the DCMD module. Thus, more research should be carried out to improve the performance of the DCMD/SGSP coupled system. 


\section{Conclusions}

The performance of an experimental DCMD/SGSP system to achieve solar-powered thermal 353 desalination was investigated for the first time and the following conclusions can be drawn:

354 - An average fresh water flux of $\sim 1.0 \mathrm{~L} \mathrm{hr}^{-1}$ per $\mathrm{m}^{2}$ of membrane was obtained. This water 355 production is equivalent to $\sim 1.16 \times 10^{-3} \mathrm{~m}^{3} \mathrm{~d}^{-1}$ per $\mathrm{m}^{2}$ of solar pond. However, in our 356 experiments, the SGSP was far from reaching steady-state conditions while providing energy to 357 the desalination system. Therefore, the desalination system would have to be operated 358 intermittently. This is not cost-effective because it is more expensive to have larger membrane 359 areas that will not be operating continuously. For this reason, smaller membrane areas should be 360 used to reduce capital costs and to enable continuous operation.

361 - When considering that the DCMD/SGSP produces a sustainable water flux over time, an 362 average water flux of $\sim 0.12 \times 10^{-3} \mathrm{~m}^{3} \mathrm{~d}^{-1}$ per $\mathrm{m}^{2}$ of solar pond was obtained. This water 363 production was achieved with a temperature difference of $10{ }^{\circ} \mathrm{C}$ between the feed and distillate 364 solutions, and it is approximately six times greater than the water production of an $365 \quad$ AGMD/SGSP system operating under similar conditions.

366 - Although $\sim 70 \%$ of the energy extracted from the SGSP was used to drive thermal desalination, 367 only half of this energy was effectively used to transport water across the membrane (enthalpy 368 flow), and the remainder was lost by conduction in the membrane. Thus, improvements of 369 DCMD membranes and modules are a research line that could improve the performance of this 370 coupled system. In addition, by having better insulation throughout the system more energy 371 should be available for fresh water production. Thus, further investigation of membrane 372 properties, insulation of the system, or optimal design of the solar pond must be addressed in the 373 future. 


\section{Acknowledgements}

375 The authors wish to thank the Comisión Nacional de Investigación Científica y Tecnológica 376 (CONICYT), Chile, for funding project Fondecyt de Iniciación N 11121208 , the Centro de 377 Desarrollo Urbano Sustentable (CEDEUS - CONICYT/FONDAP/15110020), the Department of 378 Energy (DOE) for funding Grants DE-FG02-05ER64143 and 656-1769-01-NV-REC (Nevada 379 Renewable Energy Consortium), and the National Science Foundation (NSF) for partial funding of 380 this work by Awards NSF-EAR-0929638 and NSF-EAR-1128999. The authors greatly appreciate 381 the support of Drs. Mark B. Hausner and Jazmín Aravena. 


\section{References}

383 [1] Kummu, M., Ward, P.J., de Moel, H., Varis, O., 2010. Is physical water scarcity a new phenomenon? Global assessment of water shortage over the last two millenia. Environmental Research Letters 5, 034006, 10 pp.

[2] Kalogirou, S.A., 2005. Seawater desalination using renewable energy sources. Progress in Energy and Combustion Science 31: 242-281.

388 [3] Gude, V.G., Khandan, N.N., Deng, S., 2011. Desalination using solar energy: towars

[5] Zhu, A., Rahardianto, A., Christofides, P.D., Cohen, Y. 2010. Reverse osmosis desalination with high permeability membranes - Cost optimization and research needs. Desalination and

[6] Shannon, M.A., Bohn, P.W., Elimelech, M., Georgiadis, J.G., Mariñas, B.J., Mayes, A.M., 2008. Science and technology for water purification in the coming decades. Nature 452:301310.

[7] Eltawil, M.A., Zhengming, Z., Yuan, L.A., 2009. A review of renewable energy technologies integrated with desalination systems. Renewable and Sustainable Energy Reviews 13:22452262.

[8] Li, C., Goswami, Y., Stefanakos, E., 2013. Solar assisted seawater desalination: a review. Renewable and Sustainable Energy Reviews 19:136-163.

[9] Salata, F., Coppi, M., 2014. A first approach study on the desalination of sea water using heat transformers powered by solar ponds. Applied Energy 136:611-618.

[10] Karagiannis, I., Soldatos, P.G., 2008. Water desalination cost literature: review and assessment. Desalination 223:448-456. 
407 [11] Hickenbottom, K.L., Cath, T.Y., 2014. Sustainable operation of membrane distillation for enhancement of mineral recovery from hypersaline solutions. Journal of Membrane Science 454:426-435.

[12] Mathioulakis, E., Belessiotis, V., Delyannis, E. 2007. Desalination by using alternative energy: Review and stateof-the-art. Desalination 203:346-365.

412 [13] Seckler, D., Barker, R., Amarasinghe, U., 1999. Water scarcity in the twenty-first century. International Journal of Water Resources Development 15(1-2):29-42.

[14] Cath, T., Adams, V., Childress, A. E., 2004. Experimental study of desalination using direct contact membrane distillation: a new approach to flux enhancement. Journal of Membrane Science 228:5-16.

[15] Curcio, E., Drioli, E., 2005. Membrane distillation and related operations - A review. Separation and Purification Reviews 34:35-86.

[16] El-Bourawi, M.S., Ding, Z., Ma, R., Khayet, M., 2006. A framework for better understanding membrane distillation separation process. Journal of Membrane Science 285:4-29.

[17] Hwang, H.J., He, K., Gray, S., Zhang, J., Moon, I.S., 2011. Direct contact membrane distillation (DCMD): Experimental study on the commercial PTFE membrane and modeling. Journal of Membrane Science 371: 90-98.

[18] Rabl, A., Nielsen, C., 1975. Solar ponds for space heating. Solar Energy 17:1-12.

[19] Suárez, F., Tyler, S.W., Childress, A.E., 2010a. A fully coupled transient double-diffusive convective model for salt-gradient solar ponds. International Journal of Heat and Mass Transfer 53(9-10):1718-1730.

[20] Lu, H., Walton, J., Swift, A., 2001. Desalination coupled with salinity-gradient solar ponds. Desalination 136:13-23.

[21] Leblanc, J., Akbarzadeh., A., Andrews, J., Lu., H., Golding, P., 2011. Heat extraction methods from salinity-gradient solar ponds and introduction of a novel system of heat extraction for improved efficiency. Solar Energy 85:3103-3142. 
[22] Lu, H., Swift, A.P., Hein, H.D., Walton, J.C., 2004. Advancements in Salinity Gradient Solar Pond Technology Based on Sixteen Years of Operational Experience. Journal of Solar Energy Engineering 126:759-767.

[23] Weeks, D.D., Long, S.M., Emery, R.E., Bryant, H.C., 1981. What Happens when a Solar Pond Boils? In Southwest Regional Conference for Astronomy \& Astrophysics, Albuquerque, New Mexico.

[24] Qtaishat, M.R., Banat, F., 2013. Desalination by solar powered membrane distillation systems. Desalination 308:186-197.

[25] Suárez, F., Tyler, S.W., Childress, A.E., 2010b. A theoretical study of a direct contact membrane distillation system coupled to a salt-gradient solar pond for terminal lakes reclamation. Water Research 44(15):4601-4615.

[26] Camacho, L.M.C., Dumée, L., Zhang, J., Li, J., Duke, M., Gomez, J., Gray, S., 2013. Advances in membrane distillation for water desalination and purification applications. Water 5:94-196.

[27] Saleh, A., Qudeiri, J.A., Al-Nimr, M.A., 2011. Performance investigation of a salt gradient solar pond coupled with desalination facility near the Dead Sea. Energy 36:922-931.

[28] Mericq, J-P., Laborie, S., Cabassud, C., 2011. Evaluation of systems coupling vacuum membrane distillation and solar energy for seawater desalination. Chemical Engineering Journal 166:596-606.

[29] Suárez, F., Aravena, J.E., Hausner, M.B., Childress, A.E. \& Tyler, S.W., 2011. Assessment of a vertical high-resolution distributed-temperature-sensing system in a shallow thermohaline environment. Hydrology and Earth System Sciences 15(3):1081-1093

[30] Suárez, F., Ruskowitz, J.A., Childress, A.E. \& Tyler, S.W., 2014. Understanding the expected performance of large-scale solar ponds from laboratory-scale observations. Applied Energy 117:1-10. 
458 [31] Al-Obaidani, S., Curcio, E., Macedonio, F., Di Profio, G., Al-Hinai, H., Drioli, E., 2008. Potential of membrane distillation in seawater desalination: termal efficiency, sensitivity study and cost estimation. Journal of Membrane Science 323:85-98.

461 [32] Phattaranawik, J., Jiraratananon, R., Fane, A. G., 2003. Heat transport and membrane distillation coefficients in direct contact membrane distillation. Journal of Membrane Science 212:177-193.

[33] Hausner, M.B, Suárez, F., Glander, K.E., van de Giesen, N., Selker, J.S., Tyler, S.W., 2011. Calibrating single-ended fiber-optic Raman spectra distributed temperature sensing data. Sensors 11(11):10859-10879.

[34] Wetzel, R.G., Likens, G.E., 1991. Limnological Analyses. Third ed, ed. Springer-Verlag, New York.

[35] Schofield, R., Fane, A. G., Fell, C. J. D., Macoun, R., 1990. Factors affecting flux in membrane distillation. Desalination 77(1-3):279-294.

[36] Suárez, F., 2010. Salt-gradient solar ponds for renewable energy, desalination and reclamation of terminal lakes. Ph.D. thesis, University of Nevada, Reno.

[37] Suárez, F., Childress, A.E. \& Tyler, S.W., 2010c. Temperature evolution of an experimental salt-gradient solar pond. Journal of Water and Climate Change 1(4):246-250.

[38] Beniwal, R.S., Singh, R., 1987. Calculation of thermal efficiency of salt gradient solar ponds. Heat Recovery Systems \& CHP 7: 497-516.

[39] Karakilcik, M., Dincer, I., 2008. Exergetic performance analysis of a solar pond. International Journal of Thermal Sciences 47: 93-102.

[40] Mazidi, M., Shojaeefard, M.H., Mazidi, M.Sh., Shojaeefard, H., 2011. The two-dimensional modeling of a salt-gradient solar pond with wall shading effect and thermo-physical properties dependent on temperature and concentration. Journal of Thermal Science 20(4):362-370. 
483 [41] Solis, S., 1999. Water desalination by membrane distillation coupled with a solar pond. Ms. 484 Thesis, University of Texas at El Paso, El Paso.

485 [42] Kumar, A., Kishore, V.V.N., 1999. Construction and operation experience of a 6000-m² solar 486 pond at Kutch, India. Solar Energy 65:237-249.

487 [43] Bronicki, L.Y., 2002. Solar Ponds. Encyclopedia of Physical Science and Technology 15:149$488 \quad 166$.

489 [44] Ruskowitz, J.A. 2012. Salt-gradient solar pond and membrane distillation system for water 490 desalination powered by renewable energy. Ms. Thesis, University of Nevada, Reno, Reno.

491 [45] Ruskowitz, J.A., Suárez, F., Tyler, S.W., Childress, A.E., 2014. Evaporation suppression and 492 solar energy collection in a salt-gradient solar pond. Solar Energy 99:36-46.

493 
Table 1. Probability distributions of the input parameters $(X)$ used in the Monte Carlo simulations. : mean value; $\sigma$ : standard deviation. $X \in(a, b)$.

\begin{tabular}{|c|c|c|}
\hline Variable & $\begin{array}{l}\text { Probability } \\
\text { distribution }\end{array}$ & Parameters \\
\hline $\begin{array}{l}\text { Feed temperature }{ }^{*} \\
\mathrm{~T}_{\mathrm{f}}\left({ }^{\circ} \mathrm{C}\right)\end{array}$ & Normal & $=34.3 ; \sigma=0.1$ \\
\hline $\begin{array}{l}\text { Distillate temperature }{ }^{*} \\
\qquad \mathrm{~T}_{\mathrm{p}}\left({ }^{\circ} \mathrm{C}\right)\end{array}$ & Normal & $=24.0 ; \sigma=0.1$ \\
\hline $\begin{array}{c}\text { Tortuosity }^{* *} \\
\tau(-)\end{array}$ & Truncated normal & $\begin{array}{l}=1.43 ; \sigma=0.143 \\
\mathrm{a}=1.0 ; \mathrm{b}=2.0\end{array}$ \\
\hline $\begin{array}{l}\text { Effective thermal conductivity }{ }^{* *} \\
\qquad k_{\mathrm{m}}\left(\mathrm{W} \mathrm{m}^{-1} \mathrm{C}^{-1}\right)\end{array}$ & Normal & $=0.046 ; \sigma=0.005$ \\
\hline $\begin{array}{l}\text { Partial pressure of air entrapped in pores } \\
\qquad p_{\mathrm{a}}(\mathrm{kPa})\end{array}$ & Normal & $=86 ; \sigma=7.0$ \\
\hline $\begin{array}{l}\text { Heat transfer coefficient in feed side }{ }^{* *} \\
\qquad h_{\mathrm{f}}\left(\mathrm{W} \mathrm{m}^{-2}{ }^{\circ} \mathrm{C}^{-1}\right)\end{array}$ & Uniform & $a=1,300 ; b=2,000$ \\
\hline $\begin{array}{l}\text { Heat transfer coefficient in distillate side } \\
\qquad h_{\mathrm{p}}\left(\mathrm{W} \mathrm{m}{ }^{-2} \mathrm{C}^{-1}\right)\end{array}$ & Uniform & $a=1,300 ; b=2,000$ \\
\hline $\begin{array}{l}\text { Heat extracted from the solar pond }{ }^{*} \\
\qquad q_{\mathrm{USE}}^{\prime \prime}(\mathrm{W})\end{array}$ & Normal & $=231.3 ; \sigma=21.7$ \\
\hline $\begin{array}{c}\text { Conductive heat losses in solar pond } \\
\text { plumbing }{ }^{*} \\
q_{\mathrm{SGSP}}^{\text {cond }}(\mathrm{W})\end{array}$ & Uniform & $=43.7 ; \sigma=1.1$ \\
\hline
\end{tabular}


Table 2. Water fluxes in the desalination system and energy budget in the coupled system for the first 2.5 hours 504 of experimentation. $T_{\mathrm{f}}=34 .{ }^{\circ} \mathrm{C} ; T_{\mathrm{p}}=24.0^{\circ} \mathrm{C} ; v_{\mathrm{f}}=0.21 \mathrm{~m} \mathrm{~s}^{-1} ; v_{\mathrm{p}}=0.33 \mathrm{~m} \mathrm{~s}^{-1} ; S_{\mathrm{f}}=0 ; p_{\mathrm{a}}=86 \mathrm{kPa} ; \tau=1.43 ; k_{\mathrm{m}}=$ $505 \quad \mathbf{0 . 0 4 6} \mathrm{W} \mathrm{m}^{-1}{ }^{\circ} \mathrm{C}^{-1}$.

\begin{tabular}{ccccccc}
\hline$J$ & $q_{\mathrm{USE}}^{\prime \prime}$ & $q_{\mathrm{m}}$ & $q_{\mathrm{m}}^{\mathrm{v}}$ & $q_{\mathrm{m}}^{\mathrm{c}}$ & $q_{\mathrm{SGSP}}^{\text {cond }}$ & $q_{\mathrm{SYST}}^{\text {other }}$ \\
$\left(\mathrm{L} \mathrm{m}^{-2} \mathrm{hr}^{-1}\right)$ & $(\mathrm{W})$ & $(\mathrm{W})$ & $(\mathrm{W})$ & $(\mathrm{W})$ & $(\mathrm{W})$ & $(\mathrm{W})$ \\
\hline $1.14 \pm 0.12$ & $231.3 \pm 21.7$ & $157.7 \pm 10.8$ & $80.9 \pm 8.8$ & $76.8 \pm 7.8$ & $43.7 \pm 1.1$ & $29.9 \pm 24.3$
\end{tabular}

$506 \quad$ Average value \pm standard deviation.

507

508 
Figure 1. Diagram of the experimental setup. The symbols $P, E C, F$, and $T$ represent pumps, electrical conductivity probes, flow meters, and temperature sensors, respectively; UCZ, NCZ and LCZ are upper convective zone, non-convective zone, and lower convective zone, respectively.

Figure 2. Thermal behavior inside the solar pond. Temperature was measured using a vertical high-resolution DTS system with a spatial resolution of $1.1 \mathrm{~cm}$. A temperature resolution of $0.06{ }^{\circ} \mathrm{C}$ was achieved when the data were collected using integration intervals of 30 seconds. The desalination experiment started after thermal quasisteady state was achieved and continued for 45 hours. Heat was extracted at a depth of $\sim 0.5 \mathrm{~m}$.

Figure 3. Thermal behavior inside the solar pond during the desalination experiment: (a) temperature profile inside the solar pond at different times. The depth of the UCZ-NCZ and NCZ-LCZ interfaces are shown at the right side of the graph, and the depth where heat was extracted is shown at the left side of the graph; (b) temporal evolution of the heat content inside the solar pond. The inset shows a zoom of the first 2.5 hours of the desalination experiment.

Figure 4. Thermal desalination experiment: (a) water flux and cumulative distillate in the desalination system; (b) water flux and temperatures in the desalination system when steady-state conditions were observed.

Figure 5. Monte Carlo simulations $\left(n=10^{6}\right)$ show that experimental water fluxes $\left(J_{\exp } \pm \sigma_{\text {exp }}\right)$ are within the range of the modeled water fluxes $\left(J_{\text {mod }} \pm \sigma_{\text {mod }}\right)$. 


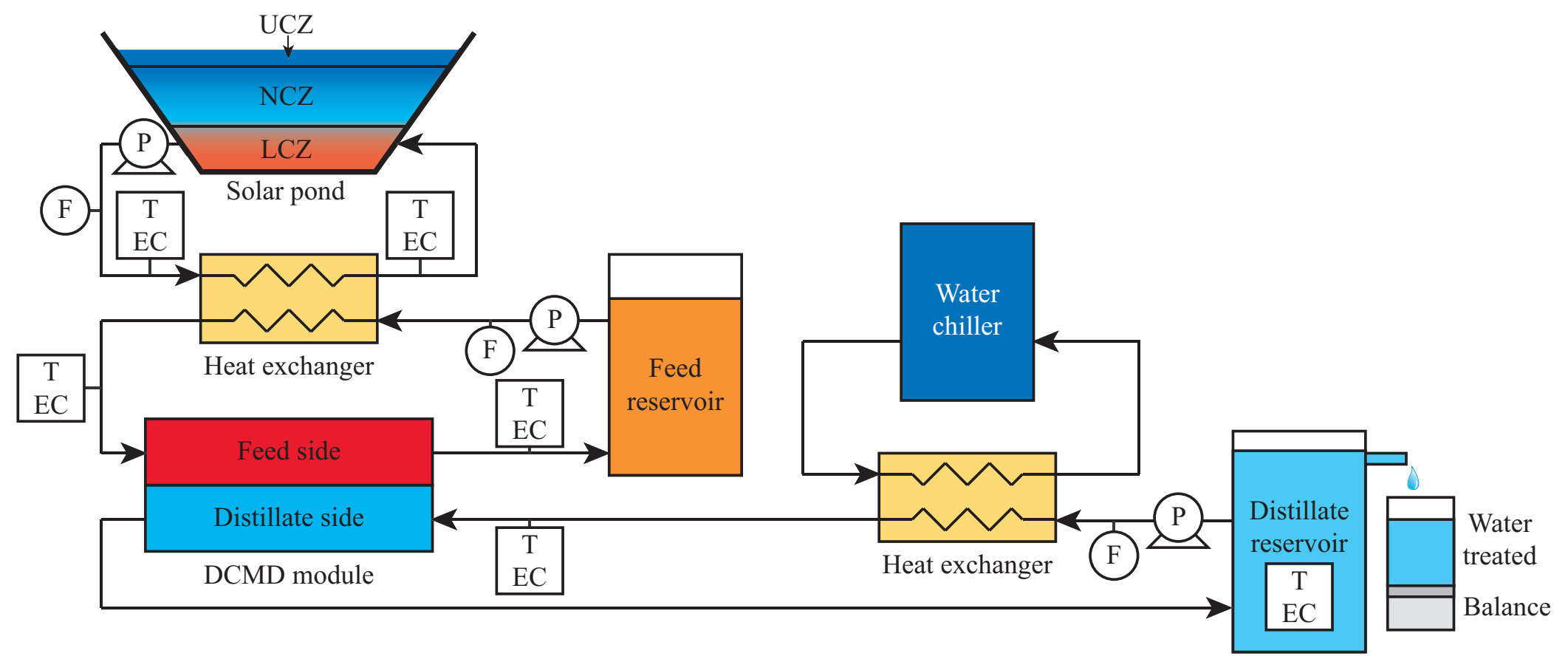

Figure 1. Diagram of the experimental setup. The symbols P, EC, F, and T represent pumps, electrical conductivity probes, flow meters, and temperature sensors, respectively; UCZ, NCZ and LCZ are upper convective zone, nonconvective zone, and lower convective zone, respectively. 

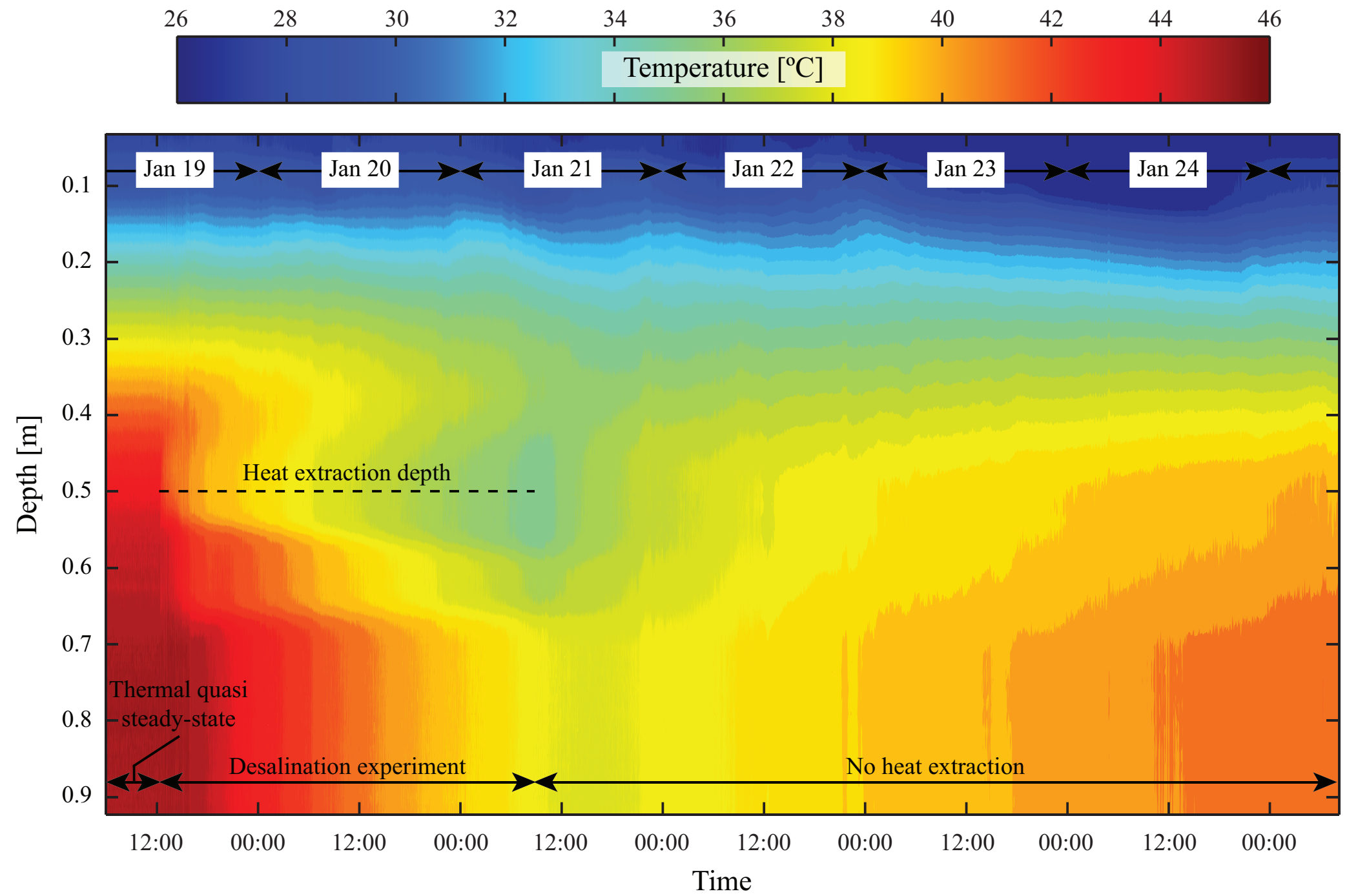

Figure 2. Thermal behavior inside the solar pond. Temperature was measured using a vertical high-resolution DTS system with a spatial resolution of $1.1 \mathrm{~cm}$. A temperature resolution of $0.06{ }^{\circ} \mathrm{C}$ was achieved when the data were collected using integration intervals of 30 seconds. The desalination experiment started after thermal quasi-steady state was achieved and continued for 45 hours. Heat was extracted at a depth of $\sim 0.5 \mathrm{~m}$. 


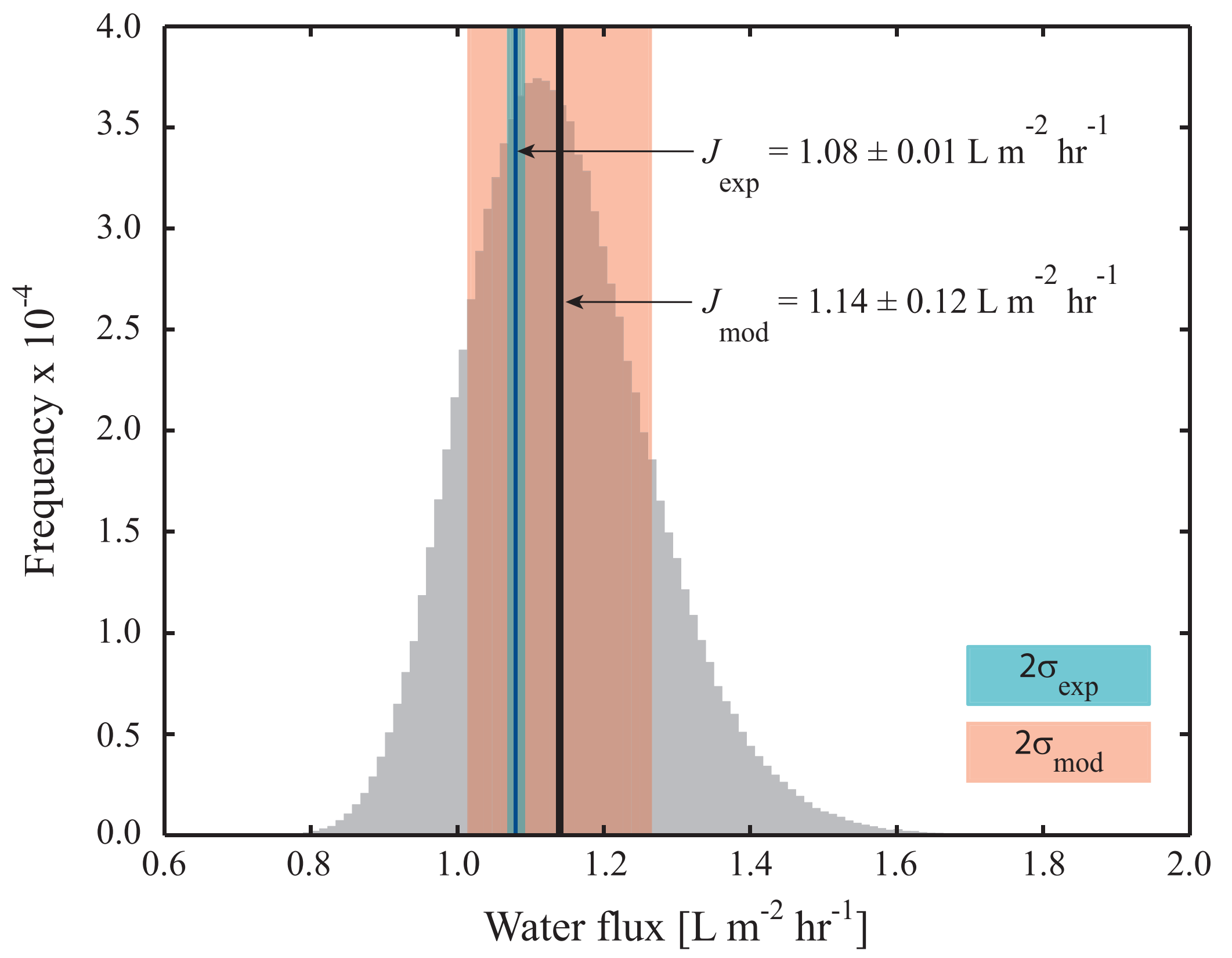

Figure 5. Monte Carlo simulations $\left(n=10^{6}\right)$ show that experimental water fluxes $\left(\mathrm{J}_{\exp } \pm \sigma_{\text {exp }}\right)$ are within the range of the modeled water fluxes $\left(\mathrm{J}_{\text {mod }} \pm \sigma_{\text {mod }}\right)$. 